\title{
Tracheostomy in a thoracic surgical unit
}

\author{
D. B. CLARK E ${ }^{1}$ \\ From Harefield Hospital, Harefield, Middlesex
}

The first authenticated instance in which tracheostomy was performed was in 1546 when Brasavola (Guthrie, 1944) relieved respiratory obstruction in a patient who was probably suffering from Ludwig's angina. From then until the second world war obstruction of the upper respiratory passages remained the sole indication for this operation. It was a procedure regarded with distrust, being in fact referred to as 'the scandal of surgery', but in recent years its indications have been extended, its potentialities more precisely defined, and its limitations more critically appraised. In this study an analysis has been made of the tracheostomies performed during the past five years in a thoracic surgical unit. This unit consists of 87 beds which also serve general medical and chest wards.

\section{CLINICAL MATERIAL}

INDICATION FOR TRACHEOSTOMY A total of 69 tracheostomies were performed in five years. Of these, $52 \%$ followed lung resections; the remainder were carried out after cardiac and oesophageal surgery, in patients with respiratory failure who had been referred from the medical wards, for respiratory obstruction, chest injury, and in unconscious patients who were incapable of coughing (Table I). In other series the most frequent indications have been head and chest injuries and paralysis of the muscles of respiration

TABLE I

CONDITIONS IN WHICH TRACHEOSTOMY WAS PER-

\begin{tabular}{|c|c|c|c|c|c|}
\hline Condition & & No. & $\stackrel{\% \text { of }}{\text { Total }}$ & Deaths & $\%$ of \\
\hline $\begin{array}{l}\text { Pulmonary resections } \\
\text { Respiratory failure . } \\
\text { Cardiac surgery } \\
\text { Airway obstruction } \\
\text { Oesophageal surgery } \\
\text { Chest injuries } \\
\text { Unconsciousness } \\
\text { Miscellaneous }\end{array}$ & $\begin{array}{l}\cdots \\
\cdots \\
\cdots \\
\cdots \\
\cdots \\
\cdots\end{array}$ & $\begin{array}{r}36 \\
9 \\
7 \\
6 \\
3 \\
2 \\
2 \\
4\end{array}$ & $\begin{array}{l}52 \\
13 \\
10 \cdot 3 \\
8 \cdot 7 \\
4 \cdot 3 \\
2 \cdot 9 \\
2 \cdot 9 \\
5 \cdot 8\end{array}$ & $\begin{array}{r}16 \\
4 \\
4 \\
0 \\
1 \\
1 \\
1 \\
2\end{array}$ & $\begin{array}{c}55 \\
13 \cdot 8 \\
13 \cdot 8 \\
0 \\
3 \cdot 4 \\
3 \cdot 4 \\
3 \cdot 4 \\
6 \cdot 8\end{array}$ \\
\hline Total & $\ldots$ & 69 & & 29 & 42 \\
\hline
\end{tabular}

1 Present address: The United Birmingham Hospitals
(Nelson, 1958 ; Head, 1961 ; Meade, 1961 ; Watts, 1963).

The patients referred by physicians had gross destruction of lung tissue resulting from chronic bronchitis and emphysema or tuberculosis, and as a result of superadded infection or spontaneous pneumothorax they had progressed to a state of respiratory failure with carbon dioxide retention.

Four tracheostomies were performed for less precisely defined conditions which included myasthenia gravis, the rupture of an empyema into the bronchial tree, and in two cases malignant cachexia (Table I).

The indications for tracheostomy are retention of sputum because of an ineffective cough, inadequate ventilation of the lungs, obstruction of the airway above the tracheal level, and after cardiac surgery (Table II). Björk and Engström (1955) suggest that an arterial $\mathrm{PCO}_{2}$ above $70 \mathrm{~mm} . \mathrm{Hg}$ is a strong indication for tracheostomy, but in this series we have been guided by the clinical signs of hypercapnia, i.e., shallow respiration, stupor, a hot flushed skin with an elevated blood pressure, and a bounding pulse. In a patient who showed signs of sputum retention, tracheostomy was usually deferred until physiotherapy had been given an adequate trial or bronchoscopic aspiration of secretions had failed to provide more than temporary relief. The timing of the operation is important. There is little to be gained from persisting with physiotherapy when it becomes obvious that nothing is being achieved other than the exhaustion of the patient. There is a large measure of truth in the adage that the right time to perform tracheostomy is when the likelihood of its being necessary is first suggested.

Intermittent positive pressure ventilation using a mechanical respirator was used in $21.8 \%$ of cases. The conditions in which tracheostomy was performed are detailed in Table I and the indications for tracheostomy in these conditions are given in Table II.

TRACHEOSTOMY IN LUNG RESECTIONS An analysis of the 36 lung resections shows that $50 \%$ of the tracheostomies in this group followed left 
TABLE II

INDICATIONS FOR TRACHEOSTOMY

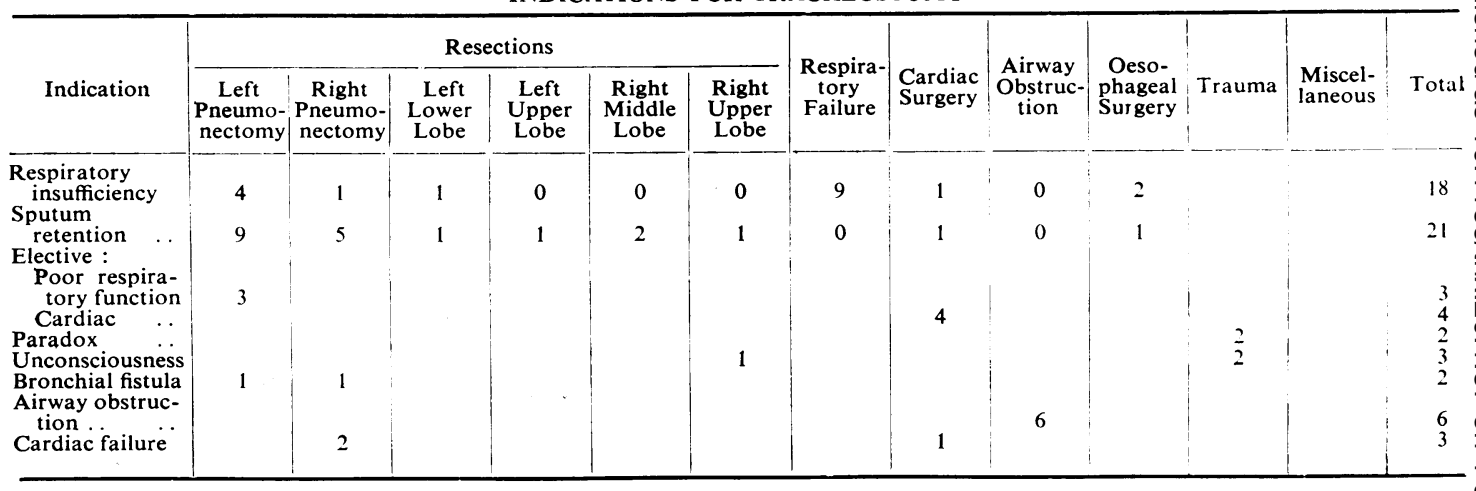

pneumonectomy (Table III). In nearly half of these there was evidence of damage to the left recurrent laryngeal nerve which must have been sustained when the sub-aortic lymph nodes were excised. Right pneumonectomy accounted for $25 \%$ of the total, and lobectomies for the remaining $25 \%$ (Table III).

\section{TAB LE III}

ANALYSIS OF TRACHEOSTOMIES IN PULMONARY RESECTION

\begin{tabular}{|c|c|c|c|c|}
\hline Type of Resection & No. & $\begin{array}{l}\% \text { of } \\
\text { Total }\end{array}$ & Deaths & $\begin{array}{l}\% \text { of Total } \\
\text { Resections }\end{array}$ \\
\hline $\begin{array}{l}\text { L. pneumonectomy } \\
\text { R. pneumonectomy } \\
\text { L. lower lobectomy } \\
\text { L. upper lobectomy } \\
\text { R. middle-lower lobec- } \\
\text { tomy . } \\
\text { R. upper lobectomy }\end{array}$ & $\begin{array}{r}18 \\
9 \\
2 \\
1 \\
2 \\
4\end{array}$ & $\begin{array}{l}50 \\
25 \\
5 \cdot 5 \\
2 \cdot 8 \\
5 \cdot 5 \\
11 \cdot 1\end{array}$ & $\begin{array}{l}8 \\
3 \\
0 \\
1 \\
1 \\
1 \\
3\end{array}$ & $\begin{array}{l}50 \\
18 \cdot 75 \\
0 \\
6 \cdot 25 \\
6 \cdot 25 \\
18 \cdot 25\end{array}$ \\
\hline Total & 36 & & 16 & 55 \\
\hline
\end{tabular}

Sputum retention was the commonest indication. In these cases an inadequate cough resulted from general weakness, pain or paralysis of one vocal cord. Ventilatory inadequacy, the next commonest cause, resulted from poor function of the residual lung, shallow respiration because of pain or weakness, and from paradoxical movement either of the chest wall, when part of this had been excised, or of the diaphragm when the phrenic nerve had been damaged at operation (Björk and Engström, 1955 ; Minnis and Griffin, 1961). When pre-operative lung function studies indicated a marginal respiratory reserve elective tracheostomy was carried out at the time of operation in three instances.

By preventing the build-up of intra-bronchial pressure before explosive decompression in the act of coughing, tracheostomy may be used electively to take some of the strain from a doubtful bronchial suture line after pneumonectomy. It may $\vec{\bullet}$ be indicated for the same reasons after sleeve $\stackrel{\odot}{\circ}$ resection, with the added incentive that marginal. respiratory function may well have been an indication for such a procedure and that the residual lung on the side operated upon is peculiarly liable to sputum retention. The development of a bronchopleural fistula with spill-over into the $\stackrel{\mathbb{Q}}{\mathscr{Q}}$ contralateral lung has been a further indication in two instances in this series.

TRACHEOSTOMY IN OTHER CONDITIONS The value of early tracheostomy in major chest injuries has been established.

There are only two cases in this series because $\stackrel{0}{x}$ this hospital is not served by a casualty department. Both had paradoxical movement of the chest wall, and in each the mere performance of $\delta$ tracheostomy reduced the paradox to such a degree that positive pressure respiration was 은 unnecessary.

The six cases of airway obstruction were due to malignancy at laryngeal level, Ludwig's angina, $\bar{N}$ and laryngeal oedema.

Tracheostomy is of value in respiratory failure $N$ in patients with gross diminution of pulmonary $\underset{\omega}{N}$ function for three reasons: by reducing the dead 0 space by approximately $100 \mathrm{ml}$. the alveolar 0 ventilation is nearly doubled; when carbon dioxide retention is established, assisted ventilation with $\stackrel{\mathcal{P}}{?}$ a mechanical respirator not only washes out excess 0 $\mathrm{CO}_{2}$ but also corrects anoxia; the excessive $\stackrel{0}{\circ}$ bronchial secretion usually found in these patients can be effectively sucked out.

Tracheostomy combined with intermittent positive pressure respiration may assist patients subjected to cardiac surgery in several ways. It $\delta$ 
ensures adequate oxygenation at all times in a group of patients in whom anoxia can be critical or even fatal. In the resting subject, about $25 \%$ of work done by the heart is expended in the mechanical work of respiration. In mitral valve disease this figure may be more than doubled. It follows therefore that by taking over respiration with a ventilator this burden is largely removed from the heart. Further, the increase in gas tension in the alveoli produced by I.P.P.R. tends to counteract those forces which produce pulmonary oedema. It has been the practice in this unit of late to carry out an elective tracheostomy in patients with mitral incompetence who have a high left atrial pressure after surgery, and routinely after total correction of Fallot's tetralogy.

MORTALITY On first inspection, an overall mortality of $42 \%$ is alarming and liable to obscure the very real value of tracheostomy. Of these 29 deaths, however, 15 were from unrelated causes, such as pulmonary embolus, carcinomatosis or haemorrhage, which could not be attributed to the tracheostomy; nor could these deaths be expected to have been avoided because tracheostomy had been performed.

Of the remaining 14 deaths, eight (57\%) were attributable to bronchopneumonia (Table IV). Watts (1963) reports a mortality of $2 \%$, but the causes of death were directly attributable to the operation itself and do not include bronchopneumonia. Of his 212 cases, 37 came to postmortem examination, and in 26 of these there was evidence of bronchopulmonary infection; in 16 this was thought to be the cause of death. It will be argued that some of these infections were the inexorable progress of the condition for which the tracheostomy was done in the first place, but Gotsman and Whitby (1964) carried out bacteriological studies in a group of 29 patients who underwent tracheostomy and these cast a disquieting light on this matter. Of their 29 patients, six died within three days and were excluded from the study. Of the remaining 23,19 developed the clinical signs of infection. The infecting organism cultured from the trachea was in no case the same as those present in the sputum before tracheostomy; 11 were infections with penicillinresistant staphylococci and five were due to Pseudomonas pyocanea. Their studies showed that these organisms were derived from the hospital environment. They must have been introduced into the trachea either by the suction catheter or from the patients' own skin. In two cases, death resulted from bronchopleural fistula and in four from respiratory failure. Six patients had tracheostomy performed after having sustained an injury to the recurrent laryngeal nerve at left pneumonectomy; five of these died. There were no immediate deaths in the group which had airway obstruction above tracheal level. The fact that five out of nine patients who would inevitably have died from respiratory failure due to degenerative lung disease with superadded infection were saved is sufficient proof of the efficacy of tracheostomy in this condition.

The highest mortality in lung resection was in the left pneumonectomy group (eight deaths).

If mortality is correlated with the day after operation on which tracheostomy was performed, it is evident that those in whom difficulties were anticipated by the performance of an elective tracheostomy at the time of operation did best (one death in six elective tracheostomies). Thereafter there is little difference in mortality between those in whom the need for tracheostomy became evident on the first post-operative day or on the fifth. The fact that six out of seven tracheostomies performed as an emergency at the time of operation were followed by death is a reflection of the gravity of the condition for which they were carried out, e.g., after cardiac arrest.

A total of 49 tracheostomies were performed after operation with an overall mortality of $45 \%$.

No single indication is more likely to result in death than any other; the survival figures after tracheostomies performed for respiratory insufficiency and sputum retention are the same (Table V).

Table VI shows the age distribution in this series.

TABLE IV

MORTALITY AFTER TRACHEOSTOMY

\begin{tabular}{|c|c|c|c|c|c|c|c|c|c|}
\hline \multicolumn{4}{|c|}{ Cause of Death } & $\begin{array}{c}\text { Lung } \\
\text { Resections }\end{array}$ & $\begin{array}{l}\text { Cardiac } \\
\text { Surgery }\end{array}$ & $\begin{array}{c}\text { Oesophageal } \\
\text { Surgery }\end{array}$ & Trauma & $\begin{array}{c}\text { Respiratory } \\
\text { Failure }\end{array}$ & Total \\
\hline $\begin{array}{l}\text { Bronchopneumonia } \\
\text { Respiratory failure } \\
\text { Bronchopleural fistula }\end{array}$ & $\begin{array}{l}\cdots \\
\cdots \\
\cdots\end{array}$ & $\begin{array}{l}\cdots \\
\cdots \\
\cdots\end{array}$ & $\begin{array}{l}\cdots \\
\cdots \\
\cdots\end{array}$ & $\begin{array}{l}4 \\
2 \\
1\end{array}$ & 1 & 1 & 1 & $\begin{array}{l}2 \\
2\end{array}$ & $\begin{array}{l}8 \\
5 \\
1\end{array}$ \\
\hline Total $\ldots$ & . & .. & $\ldots$ & 7 & 1 & 1 & 1 & 4 & 14 \\
\hline
\end{tabular}


TABLE V

MORTALITY RELATED TO DAY AFTER OPERATION

\begin{tabular}{ll|c|c|c|c|c|c|c}
\hline & Elective & $\begin{array}{c}\text { Emergency } \\
\text { on the } \\
\text { Table }\end{array}$ & \multicolumn{5}{|c}{ Post-operative Day } \\
\cline { 4 - 9 } & & 1 & 2 & 3 & 4 & $5+$ \\
\hline Total & $\cdots$ & 6 & 7 & 8 & 11 & 7 & 2 & 8 \\
\hline
\end{tabular}

T ABLE V I

MORTALITY RELATED TO AGE

\begin{tabular}{lc|c|c|c|c|c|c|c}
\hline & \multicolumn{7}{|c}{ Age (yr.) } \\
\cline { 2 - 7 } & & $0-20$ & $20-30$ & $30-40$ & $40-50$ & $50-60$ & $60-70$ & $70+$ \\
\hline $\begin{array}{l}\text { Total } \\
\text { Deaths }\end{array}$ & $\cdots$ & 5 & 2 & 1 & 5 & 23 & 28 & 4 \\
\hline
\end{tabular}

\section{DISCUSSION}

The evaluation of any surgical procedure must stem from a balance of the benefits to be obtained against the hazards which may be incurred. Tracheostomy is a life-saving operation. The relief of respiratory distress in a patient drowning in his own bronchial secretions or the return to consciousness of a patient narcotized by carbon dioxide can be dramatic. However, an awareness of some of the disadvantages inherent in tracheostomy is essential if a successful outcome is to be achieved.

TECHNICAL CONSIDERATIONS The method of performing this operation favoured in this unit is to cut a $\cap$-shaped flap in the anterior wall of the trachea at the level of the second and third rings (Fig. 1). This is turned forward and its free edge
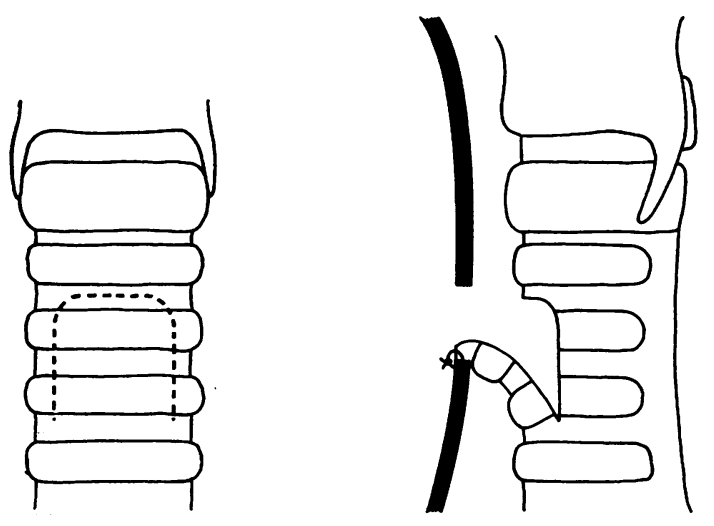

FIG. 1. Flap tracheostomy. is sutured to the inferior margin of the transverse skin incision. A vertical incision may be preferred in infants. The flap acts as a guide to direct the tube into the trachea and facilitates changing. It also circumvents the complication sometimes encountered with a simple tracheal stoma in which the tube rides out of the stoma and comes to lie in front of the trachea. We have largely discarded the metal tubes for those made of plastic except occasionally for children when the larger bore obtainable with a metal tube is an advantage. Watts (1963) condemns these portex tubes on the grounds that they are difficult to keep clean and may even become completely blocked by thick mucus. We have found that the flap so facilitates the changing of tubes that it is possible to insert a fresh one every two or three days. However, one avoidable death in this series was attributable to complete blockage of the tube.

It is sometimes argued that the flap tracheostomy gives rise to tracheal stenosis. In no case in which a flap was fashioned did this complication occur ; the only case of stricture occurred in a child in whom a large circular stoma had been made which became adherent to both the superior and inferior margins of the wound. The trachea became buckled forwards until it resembled a double-barrelled colostomy (Fig. 2a). We feel that damage to the first ring of the trachea or the creation of a too generous stoma are more important factors in the genesis of stricture. In no patient did bleeding from the tracheostomy incision give rise to difficulties, and all incisions closed satisfactorily two or three days after the tube was removed.

In one case a thick neck resulted in the trachea being at a greater depth from the skin than the length of the horizontal part of the tube. In these circumstances the tube may either refuse to lie in the trachea or it may angle so that its tip is pressed against the anterior tracheal wall with ulceration of the mucous membrane (Fig. 2b). An endotracheal tube, with its more gentle curve, may be more satisfactory in these circumstances; a flange may be improvised from rubber tubing. If the stoma is placed too far down the trachea, two difficulties are encountered. As the trachea slopes backwards a low stoma is at a greater depth from the skin than a higher one. Consequently the circumstances just described may occur in which the tip of the tube may impinge on the anterior wall of the trachea with resulting trauma to the mucous membrane. Further, a low tracheostomy carried out with the head extended may result in a stoma half-way down the trachea. After operation this will be found to lie behind 

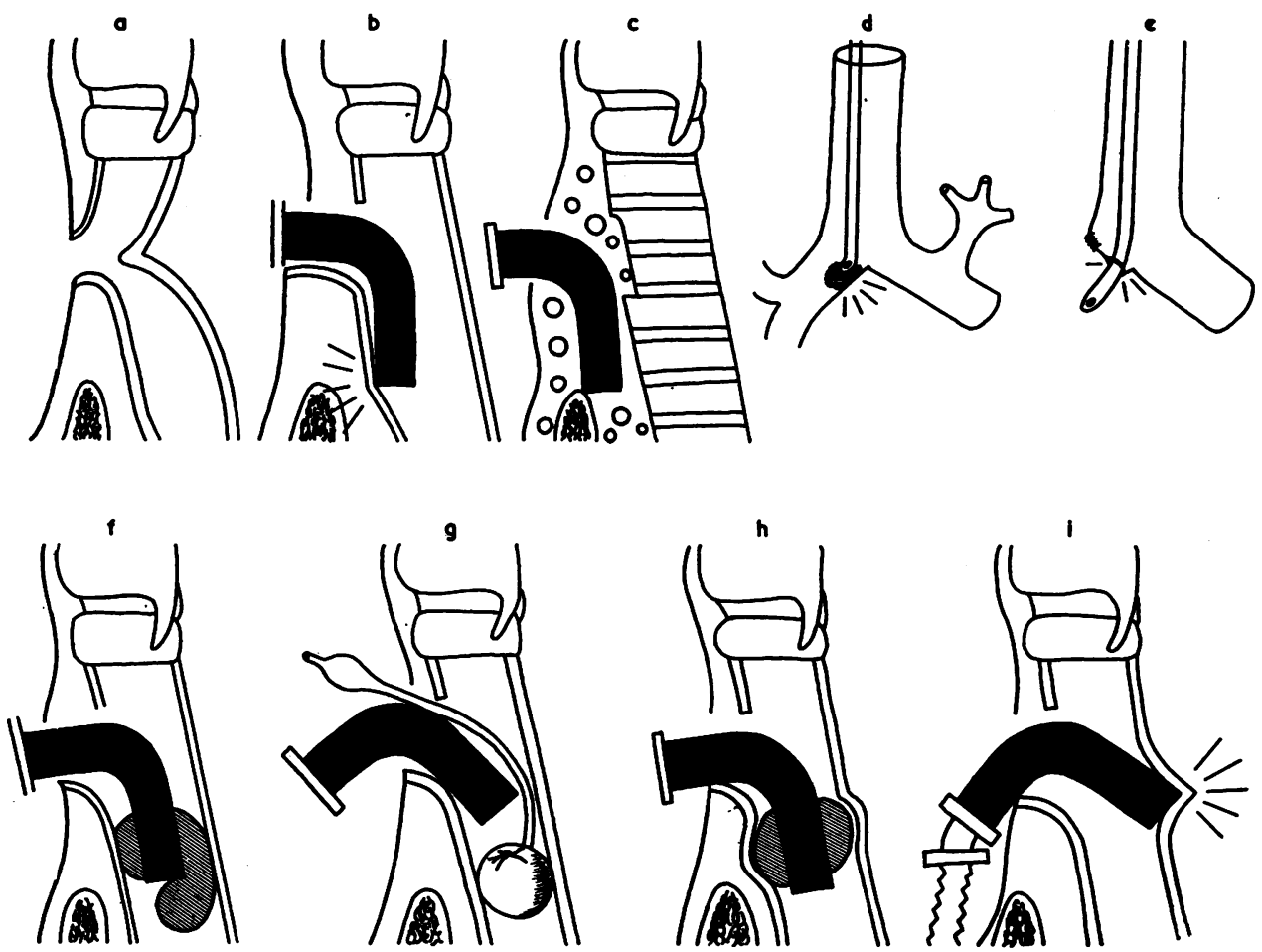

FIG. 2. Some mechanical complications of tracheostomy: (a) Forward buckling of the trachea; (b) ulceration of the anterior tracheal wall; (c) surgical emphysema due to displacement of the tube; (d) ulceration of the carina by suction catheter; (e) bronchial stump fistula; (f) herniation of over-inflated cuff; (g) detachable cuff left in trachea; (b) necrosis of tracheal rings due to cuff pressure; (i) trauma to posterior wall of trachea.

the sternum. The tube will then slip out of the trachea with resulting gross surgical emphysema (Fig. 2c).

POST-OPERATIVE MANAGEMENT There are certain disadvantages inherent in the exclusion of the upper respiratory passages. It is imperative that inspired air should be adequately humidified if secretions are not to become so viscid that they impede the normal ciliary action of the respiratory epithelium and make adequate tracheal toilet almost impossible. Of late, a commercially produced humidifier connected to a Perspex box which fits over the tracheostomy has been used, but acceptable humidification may be obtained by inserting a fine needle connected to a slow saline drip into an oxygen catheter which is placed in the mouth of the tube. Once formed, viscid secretions may be thinned by the intratracheal injection of 2 or $3 \mathrm{ml}$. of sodium bicarbonate solution.

It is significant that the greatest single cause of death in this series is bronchopneumonia, and it is difficult not to believe that infection introduced by way of the tracheostomy may play a part in this. For this reason an aseptic ritual must be observed during tracheal toilet. A fresh sterile suction tube, handled with forceps, should be used each time. It is only by regarding the repeated intubation of the trachea with the respect usually accorded to repeated intubations of the bladder that infection can be avoided. In one patient an ulcer $1 \mathrm{~cm}$. in diameter was found just to the right of the carina, at the point where the tip of an aspirating catheter might be expected to impinge (Fig. 2d). We now use a ' $Y$ ' tube inserted in the suction line so that suction may be controlled by occluding the open limb of the ' $Y$ ' with the thumb. Suction is not applied until the catheter has passed through the tracheostomy tube, otherwise difficulty is experienced because of the tip of the catheter sticking to the walls of the tube (Plum and Dunning, 1956). Undue force and 
needless prodding with the catheter is to be deprecated. It is significant that two cases of bronchopleural fistula occurred after tracheostomy following right pneumonectomy. This may well have resulted from trauma to the bronchial stump by the suction catheter, and in one instance such a fistula after pneumonectomy led to sudden death as the pneumonectomy space contents spilled into the opposite lung (Fig. 2e).

This study underlines the fact that injury to the recurrent laryngeal nerve at operation may have serious consequences. Left pneumonectomy accounted for $50 \%$ of cases in which tracheostomy was necessary after lung resection, and, of the eight deaths that occurred in this group, there was definite evidence of a paralysed vocal cord in five.

INTERMITTENT POSITIVE PRESSURE RESPIRATION This is one of the most useful indications for tracheostomy. While an indwelling endotracheal tube is acceptable for a time, we are reluctant to persist with this for longer than 24 hours because of the risk of trauma to the vocal cords and we usually proceed to tracheostomy if the need for intermittent positive pressure respiration is likely to be prolonged.

Trouble was experienced with the inflatable cuff in three instances. In two of these, an overinflated cuff herniated over the end of the tracheostomy tube (Fig. 2f), and in one the inflatable cuff was left in the trachea when the tube was removed (Fig. 2g). It immediately produced complete tracheal obstruction. It is urged that at no time should the cuff be inflated with a greater volume of air than that necessary to produce an airtight fit, and if a removable inflatable cuff is used it should be securely stitched to the tube before insertion. Over-inflation may also lead to necrosis of the cartilaginous rings of the trachea (Watts, 1963) (Fig. 2h). Another danger is encountered if an inflatable cuff is attached to a silver tube; the weight of tubing from the ventilator may angle the tracheostomy tube so that its tip damages the posterior wall of the trachea, and perforation of the oesophagus from this source may occur (Fig. 2i).

To admit that there are certain hazards inherent in tracheostomy is not to detract from its value. It is an operation with well-defined indications, to be performed deliberately under good conditions before delay has led to the necessity for performing a hurried procedure on a moribund patient. Responsibility does not cease with the completion of the operation. For a successful outcome, conscientious post-operative management is essential.

\section{SUMMARY}

Tracheostomies performed in a thoracic surgical unit over a period of five years are examined according to the indications for which they were carried out, and the deaths which resulted are analysed. The technique of the performance and the management of tracheostomy current in this unit are described, and certain difficulties and hazards are enumerated. The importance of adequate humidification and efficient tracheal toilet is stressed if bronchopneumonia is to be avoided.

I am grateful to the consultant staff of Harefield Hospital for permission to refer to the records of their patients and to Sir Thomas Holmes Sellors, Mr. J. Leigh Collis, and Mr. J. K. Ross for much helpful advice in the preparation of this paper.

\section{REFERENCES}

Björk, V. O., and Engström, C. G. (1955). The treatment of ventilatory insufficiency after pulmonary resection by tracheostomy and prolonged artificial ventilation. J. thorac. Surg., 30, 356.

Gotsman, M. S., and Whitby, J. L. (1964). Respiratory infection following tracheostomy. Thorax, 19, 89.

Guthrie, D. (1944). Early records of tracheotomy. Bull. Hist. Med., $15,59$.

Head, J. M. (1961). Tracheostomy in the management of respiratory problems. New Engl. J. Med., 264, 587.

Meade, J. W. (1961). Tracheotomy-its complications and their management. A study of 212 cases. Ibid. 265, 519.

Minnis, J.F., and Griffin, E. H. (1961). Elective tracheostomy in patients with respiratory insufficiency who are subjected to patients with respiratory insufficiency who
pulmonary surgery. $J$. thorac. Surg., $41,437$.

Nelson, T. G. (1958). Tracheotomy-a Clinical and Experimental Study. Williams and Wilkins, Baltimore.

Plum, F., and Dunning, M. F. (1956). Trauma after tracheostomy. New. Engl. J. Med., $254,193$.

Watts, J. McK. (1963). Tracheostomy in modern practice. Brit. J. Surg., 50, 954. 